\title{
Correlation of Sonographic Grading of Fatty Changes of Liver with Lipid Profile
}

\author{
Chidananda Murthy. M ${ }^{1}$, M. V. Karthik ${ }^{1}$, Ganesh $K^{2}$, Francis N. P. Monteiro ${ }^{3}$ \\ ${ }^{1}$ Assistant Professor, Department of Radio-Diagnosis, A.J. Institute of Medical Sciences and Research Centre, ${ }^{2}$ Professor \& HOD, Department of Radio-Diagnosis, \\ A.J. Institute of Medical Sciences and Research Centre, ${ }^{3}$ Professor, Department of Forensic Medicine \& Toxicology, A.J. Institute of Medical Sciences and \\ Research Centre, NH 17, Kuntikana, Mangalore -575004.
}

\section{Abstract}

Background: Ultrasound Imaging can be used as a painless, non-invasive modality for the detection of nonalcoholic fatty liver disease (NAFLD) Aims: To determine the association of abnormal lipid profiles in persons identified with NAFLD using ultrasound. Settings and Design: Retrospective observational study design at a single Centre. Subjects and Methods: The study included subjects aged 20 to 70 years, identified with NAFLD based on ultrasound findings, with biochemical test results of lipid profile and with NAFLD graded based on ultrasound findings. Statistical Analysis used: A one way Analysis of Variation test (ANOVA) was used to compare the lipid profiles by grades of NAFLD. The lipid profiles were also categorized as optimal or normal and abnormal values and compared by grades of NAFLD. A p value of $<0.05$ was considered as statistically significant. Results: The study included 100 subjects (males=87) with a mean age of $46.1 \pm$ 11.2 years. Eighty nine subjects were categorized as grade I NAFLD, 9 as grade 2 NAFLD and 2 subjects as Grade III NAFLD. The mean \pm SD total cholesterol was $195.55 \pm 43.78$, serum triglycerides was $190.09 \pm 122.03$, HDL was $42.14 \pm 10.75$, and LDL was $120.47 \pm 36.58 \mathrm{md} / \mathrm{dL}$, cholesterol HDL ratio was $4.90 \pm 1.52$ and LDL HDL ratio was $2.92 \pm 1.07$ (range 0.56 to 5) in the study subjects. Thirty three (33.0\%) of subjects had borderline high total cholesterol and 15 (15.0\%) subjects had high total cholesterol. Twenty two (22.0\%) subjects had borderline high serum triglycerides and 33 (33.0\%) subjects had high serum triglycerides. Conclusion: An increasing dyslipidaemia was noticed with increasing severity of NAFLD graded using ultrasound imaging.

Keywords: Ultrasound, Nonalcoholic fatty liver, dyslipidemia, cholesterol, triglycerides.

Corresponding Author: Dr. Francis N. P. Monteiro, Professor, Department of Forensic Medicine \& Toxicology, A.J. Institute of Medical Sciences and Research Centre, NH 17, Kuntikana, Mangalore -575004.

Received: April 2018

Accepted: June 2018

Introduction

Non-alcoholic fatty liver disease (NAFLD) is a common cause for chronic liver disease with an increasing incidence worldwide. ${ }^{[1-3]}$ NAFLD is associated with metabolic syndrome, obesity, type 2 diabetes and dyslipidemia. ${ }^{[4-8]}$ NAFLD is also associated with an atherogenic dyslipidemia that is characterised by increased levels of serum triglycerides, decreased levels of high density lipoproteins (HDL) and increased levels of oxidised low density lipoproteins (LDL). ${ }^{[9-13]}$ The alterations in lipid and lipoprotein profiles in NAFLD are not well understood but have been attributed to dysregulated clearance of various lipoproteins and hepatic over production of very low density lipoproteins (VLDL). ${ }^{[14]}$

Ultrasound is a simple, non-invasive, easily available imaging modality with a sensitivity of $60-94 \%$ and specificity of $66-97 \%$ in NAFLD. ${ }^{[15]}$ Ultrasound for fatty liver is operator dependent as the assessment of fatty liver depends on a subjective assessment of the hepatic echogenicity and posterior attenuation of the ultrasound beam. ${ }^{[16,17]}$ In this manuscript, we describe the lipid profiles in persons with various grades of NAFLD identified through ultrasound.

\section{Subjects and Methods}

An observational study design was used to retrospectively retrieve information of persons with NAFLD graded by ultrasound at the department of Radiodiagnosis of A.J.Institute of Medical Sciences \& Research Centre, Mangalore, Karnataka, India from June 2017 to December 2017. The study protocol was approved by the institutional ethics committee and informed consent was waived due to the retrospective nature of data collection. The study included subjects aged 20 to 70 years, identified with NAFLD based on ultrasound findings and excluded subjects who were discharged to long term care facilities, pregnant women and persons with a weekly alcohol intake more than 20 gram/week.

Ultrasound exams for NAFLD were performed PHILIPS EPIC 5G and PHILIPS AFINITY 30 Ultrasonography machine using 1-5 $\mathrm{MHz}$ convex transducer. NAFLD was graded based on a visual analysis of the intensity of echogenicity with an optimal gain setting. A minimally 


\section{Murthy et al; Sanographic Groding of Fautty Changes of Liver with Lipid Profile}

increased echogenicity was categorized as Grade I [Figure $2]$, an obscuration of the echogenic walls of portal vein branches by the echogenic liver as grade II [Figure 3] and an obscuration of the diaphragmatic outline by the echogenic liver was categorized as grade III [Figure 4] NAFLD.18 Results of the biochemical tests for serum triglycerides and cholesterol done for persons identified with NAFLD were retrieved from the medical case records. A level of total cholesterol from 200 to $239 \mathrm{mg} / \mathrm{dL}$ was considered as borderline high and values $>240 \mathrm{mg} / \mathrm{dL}$ as high, values of HDL $<40 \mathrm{mg} / \mathrm{dL}$ was considered as low and values between 41 and $59 \mathrm{mg} / \mathrm{dL}$ as borderline low, values of non-HDL cholesterol $<130 \mathrm{mg} / \mathrm{dL}$ was considered as optimal, values of LDL from 130 to $159 \mathrm{mg} / \mathrm{dL}$ was considered as borderline high and values $>160 \mathrm{mg} / \mathrm{dL}$ as high, values of VLDL $\leq 30 \mathrm{mg} / \mathrm{dL}$ were considered as normal, and serum triglyceride values of $150-199 \mathrm{mg} / \mathrm{dL}$ were considered as borderline high and $>200$ as high.

The retrieved data were initially entered into a MS Excel spreadsheet and then exported to STATA version 10.0 (College Station, TX, US) for statistical analysis. The frequency distribution, mean and standard deviations were estimated for continuous variables. A one way Analysis of Variation test (ANOVA) was used to compare the lipid profiles by grades of NAFLD. The lipid profiles were also categorized as optimal or normal and abnormal values and compared by grades of NAFLD. A p value of $<0.05$ was considered as statistically significant.

\section{Results}

The study included 100 subjects with a mean age of $46.1 \pm$ 11.2 years (range 20 to 67 years, median 47.0 years). The majority of subjects in the study were males $(n=87,87.0 \%)$. Eighty nine subjects were categorized as grade I NAFLD, 9 as grade 2 NAFLD and 2 subjects as Grade III NAFLD. [Table 1] presents the distribution of NAFLD by age and sex.

Table 1: Distribution of non-alcoholic fatty liver disease (NAFLD) by age and sex in the study population.

\begin{tabular}{|c|c|c|c|}
\hline Demographics & $\begin{array}{c}\text { Grade I } \\
\text { NAFLD } \\
(\mathbf{n = 8 9 )}\end{array}$ & $\begin{array}{c}\text { Grade II } \\
\text { NAFLD } \\
(\mathbf{n = 9})\end{array}$ & $\begin{array}{c}\text { Grade III } \\
\text { NAFLD (n=2) }\end{array}$ \\
\hline Age $<40$ years & $21(23.60 \%)$ & $4(44.44 \%)$ & $2(100.00 \%)$ \\
\hline Age 40-49 years & $33(37.08 \%)$ & $2(22.22 \%)$ & $0(0.00 \%)$ \\
\hline Age 50-59 years & $28(31.46 \%)$ & $0(0.00 \%)$ & $0(0.00 \%)$ \\
\hline Age $\geq 60$ years & $7(7.87 \%)$ & $3(33.33 \%)$ & $0(0.00 \%)$ \\
\hline Male & $76(85.39 \%)$ & $9(100.00 \%)$ & $2(100.00 \%)$ \\
\hline Female & $13(14.61 \%)$ & $0(0.00 \%)$ & $0(0.00 \%)$ \\
\hline
\end{tabular}

Thirty three $(33.0 \%)$ of subjects had borderline high total cholesterol and $15(15.0 \%)$ subjects had high total cholesterol. Twenty two $(22.0 \%)$ subjects had borderline high serum triglycerides and 33 (33.0\%) subjects had high serum triglycerides. HDL was borderline low in 45 subjects and low in 48 subjects and non HDL was abnormal in 71 subjects. LDL was borderline high in 25 subjects and high in 13 subjects and VLDL was abnormal in 54 subjects. The mean \pm SD total cholesterol was $195.55 \pm 43.78$, serum triglycerides was $190.09 \pm 122.03$, HDL was $42.14 \pm 10.75$, and LDL was $120.47 \pm 36.58 \mathrm{md} / \mathrm{dL}$. The mean cholesterol HDL ratio was $4.90 \pm 1.52$ (range $1.81,10.72$ ) and the mean LDL HDL ratio was $2.92 \pm 1.07$ (range 0.56 to 5 ) in the study subjects. [Table 2] presents the distribution of lipid profiles by grades of NAFLD. The mean total cholesterol, serum triglycerides and HDL and LDL values were significantly different by grade of NAFLD (all $\mathrm{p}$ values $<0.05$ ) with increasing grade of NAFLD associated with increasing dyslipidaemia.

Table 2: Distribution of non-alcoholic fatty liver disease (NAFLD) by Lipid Profile in the study population.

\begin{tabular}{|c|c|c|c|}
\hline Demographics & $\begin{array}{c}\text { Grade I } \\
\text { NAFLD } \\
(\mathbf{n = 8 9 )}\end{array}$ & $\begin{array}{c}\text { Grade II } \\
\text { NAFLD } \\
(\mathbf{n = 9})\end{array}$ & $\begin{array}{c}\text { Grade III } \\
\text { NAFLD (n=2) }\end{array}$ \\
\hline $\begin{array}{c}\text { Borderline High } \\
\text { Total } \\
\text { Cholesterol }\end{array}$ & $31(34.83 \%)$ & $2(22.2 \%)$ & $0(0.0 \%)$ \\
\hline $\begin{array}{c}\text { High Total } \\
\text { Cholesterol }\end{array}$ & $14(15.73 \%)$ & $0(0.0 \%)$ & $1(50.0 \%)$ \\
\hline $\begin{array}{c}\text { Borderline High } \\
\text { serum } \\
\text { triglycerides }\end{array}$ & $20(22.47 \%)$ & $2(22.2 \%)$ & $0(0.0 \%)$ \\
\hline $\begin{array}{c}\text { High Total } \\
\text { serum } \\
\text { triglycerides }\end{array}$ & $31(34.83 \%)$ & $2(22.2 \%)$ & $0(0.0 \%)$ \\
\hline $\begin{array}{c}\text { Borderline low } \\
\text { HDL }\end{array}$ & $41(46.07 \%)$ & $3(33.3 \%)$ & $1(50.0 \%)$ \\
\hline Low HDL & $42(47.19 \%)$ & $5(55.56 \%)$ & $1(50.0 \%)$ \\
\hline $\begin{array}{c}\text { Abnormal non } \\
\text { HDL }\end{array}$ & $64(71.91 \%)$ & $6(66.67 \%)$ & $1(50.0 \%)$ \\
\hline $\begin{array}{c}\text { Borderline High } \\
\text { LDL }\end{array}$ & $25(28.09 \%)$ & $0(0.0 \%)$ & $0(0.0 \%)$ \\
\hline High LDL & $11(12.36 \%)$ & $1(12.50 \%)$ & $1(50.0 \%)$ \\
\hline $\begin{array}{c}\text { Abnormal } \\
\text { VLDL }\end{array}$ & $50(56.18 \%)$ & $4(44.44 \%)$ & $0(0.0 \%)$ \\
\hline
\end{tabular}

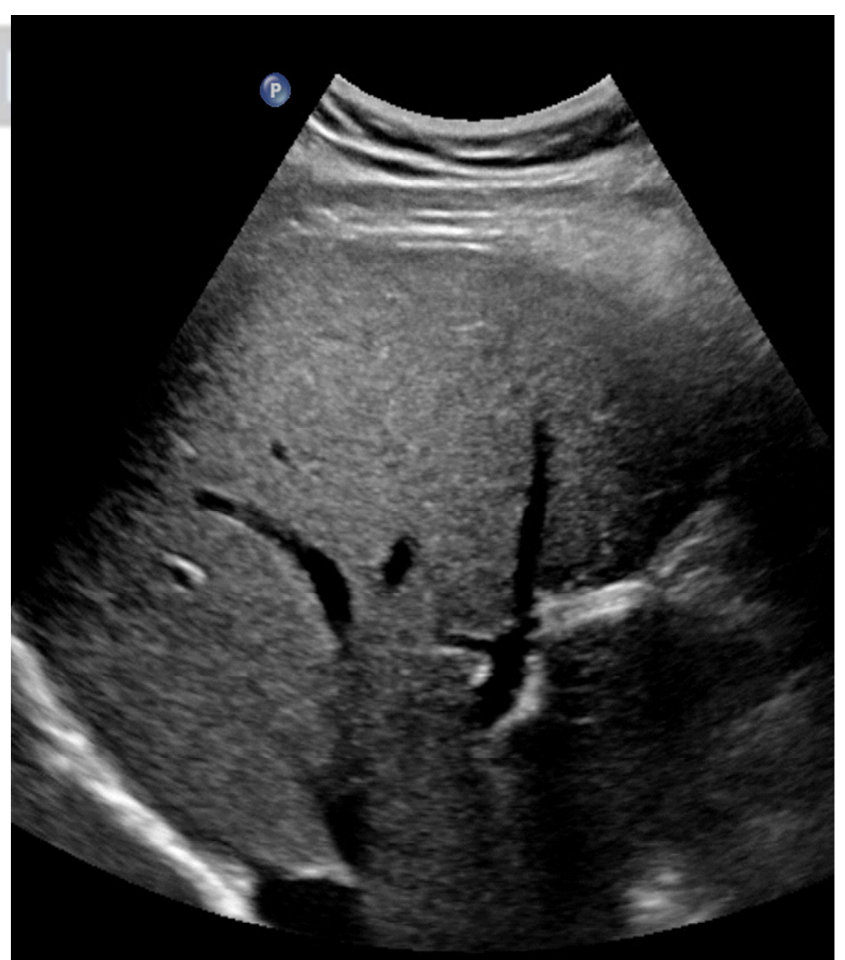

Figure 1: (Grade 0: Normal echogenicity of liver with echogenic margin of portal veins) 


\section{Murthy et al; Sanographlic Grodting of Fautty Changes of Liver with Lipid Profile}

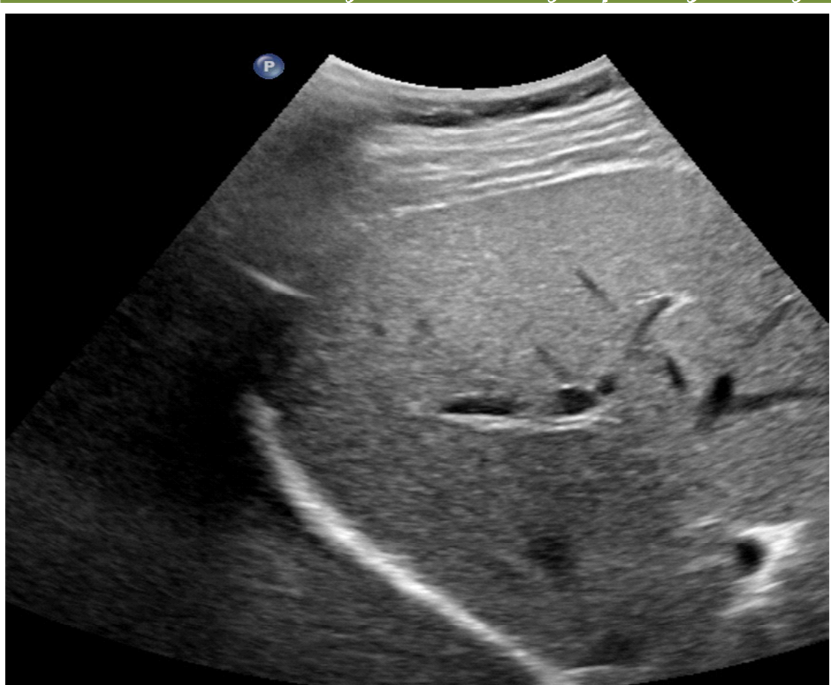

Figure 2: (Grade I: Mild increased echogenicity of liver with echogenic margin of portal veins)

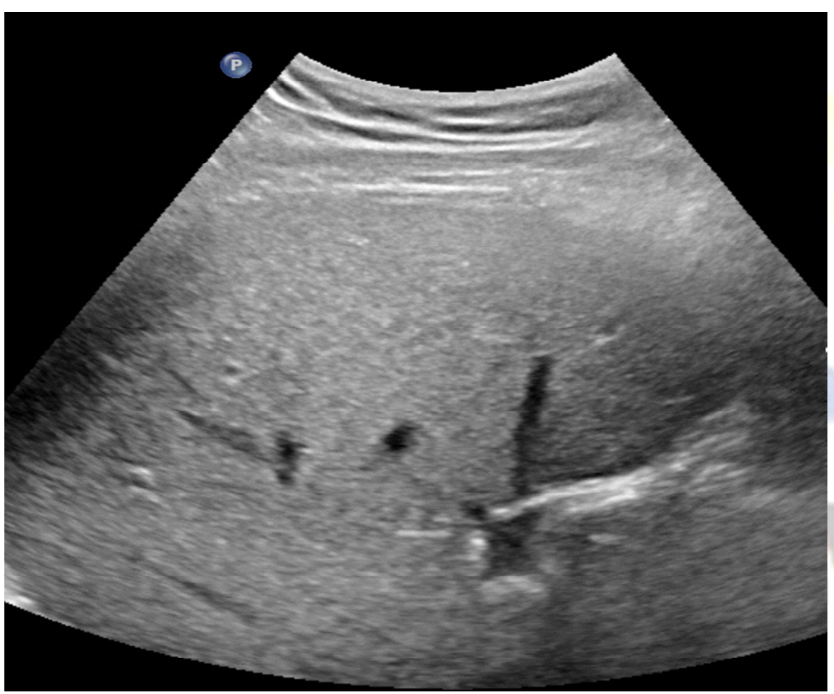

Figure 3: (Grade II: Increased echogenicity of liver with obscuration of the echogenic walls of portal veins)

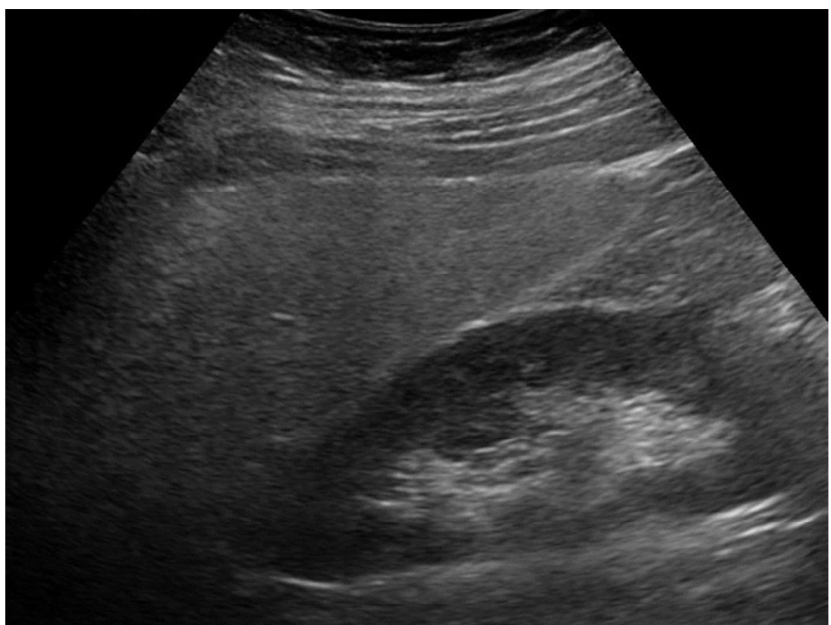

Figure 4: (Grade III: Increased echogenicity of liver with obscuration of the echogenic walls of portal veins \& diaphragmatic outline)

\section{Discussion}

The prevalence of NAFLD is estimated as varying from $9 \%$ to $32 \%$ of the general population in India. ${ }^{[19]}$ Liver biopsy has been the gold standard for the diagnosis of NAFLD, however, the procedure is invasive and has its own limitations. Imaging modalities including ultrasound are painless, non-invasive reliable alternates to identify and quantify NAFLD.

The pathogenesis of NAFLD is based on an initial triglyceride accumulation within hepatocytes that results in steatosis and is associated with insulin resistance and obesity and followed by primary lipotoxicity caused by oxidative stress from lipid peroxidation, reactive oxygen species production within hepatocytes, mitochondrial dysfunction, and inflammation. ${ }^{[20-23]}$ NAFLD is leads to an increased risk of cardiovascular disease and is associated with atherosclerotic signs including carotid plaques and coronary arterial calcium. ${ }^{[24-28]}$

NAFLD was more common among those aged 40 to 60 years in this study and was more prevalent in males compared to females. The association of NAFLD with metabolic syndrome may explain the increased prevalence in the middle ages. An increasing dyslipidaemia was noticed with increasing severity of NAFLD. These findings are consistent with previous reports in the global literature. The association of abnormal lipid profiles with NAFLD is important in India as there is an increasing prevalence of metabolic syndrome, cardiovascular diseases and other noncommunicable lifestyle diseases in India. Our study shows that ultrasound imaging may be used as a non-invasive, painless diagnostic modality for the detection of NAFLD.

\section{Conclusion}

An increasing dyslipidaemia was noticed with increasing severity of NAFLD graded using ultrasound imaging.

\section{References}

1. Browning JD, Szczepaniak LS, Dobbins R, Nuremberg P, Horton JD, Cohen JC, et al. Prevalence of hepatic steatosis in an urban population in the United States: impact of ethnicity. Hepatology. 2004;40(6): 1387-95.

2. Charlton MR, Burns JM, Pedersen RA, Watt KD, Heimbach JK, Dierkhising RA. Frequency and outcomes of liver transplantation for nonalcoholic steatohepatitis in the Unites States. Gastroenterology. 2011; 141(4): 1249-1253

3. Williams CD, Stengel J, Asike MI, Torres DM, Shaw J, Contreras M, et al. Prevalence of non-alcoholic fatty liver disease and nonalcoholic steatohepatitis among a largely middle aged population utilizing ultrasound and liver biopsy: a prospective study. Gastroenterology. 2011; 140(1):124-131

4. Ruhi CE, Everhart JE. Epidemiology of nonalcoholic fatty liver. Clin Liver Dis. 2004; 8(3):501-519.

5. Marchesini G, Bugianesi E, Forlani G, Cerelli F, Lenzi M, Manini R, et al. Nonalcoholic fatty liver, steatohepatitis, and the metabolic syndrome. Hepatology. 2003; 37(4):917-23.

6. Chalasani N, Deeg MA, Crabb DW. Systemic levels of lipid peroxidation and its metabolic and dietary correlates in patients with nonalcoholic steatohepatitis. Am J Gatroenterol. 2004:99(8): 1497 1502 .

7. Bedogni G, Miglioli L, Masutti F, Tiribelli C, Marchesini G, 


\section{Murthy et al; Sanagraphic Grading of Foutty Changes of Piver with Lipid Profile}

Bellentani S. Prevalence of and risk factors for nonalcoholic fatty liver disease: the Dionysos nutrition and liver study. Hepatology. 2005; 42(1): 44-52.

8 Neuschwander-Tetri BA Clark JM Bass NM Van Natta ML, UnalpArida A, Tonascia J, et al. NASH Clinical Research Network. Clinical, Laboratory, and histological associations in adults with nonalcoholic fatty liver disease. Hepatology. 2010; 52(3): 913-24.

9. Nseir W Shalata A, Marmor A, Assy N. Mechanisms linking nonalcoholic fatty liver disease with coronary artery disease. Dig Dis Sci. 2011;56(12):3439-3449.

10. Speliotes EK, Massaro JM, Hoffman U, Vasan RS, Meigs JB, Sahani DV, et al. Fatty liver is associated with dyslipidemia and dysglycemia independent of visceral fat: the Framingham Heart Study. Hepatology. 2010;51(6):1979-87.

11. Targher G, Day CP, Bonora E. Risk of cardiovascular disease in patients with nonalcoholic fatty liver disease. N Engl J Med. 2010; 363(14): 1341-1350.

12. Vos MB, Weber MB, Welsh J, Khatoon F, Jones DP, Whitington PF, et al. Fructose and oxidised low density lipoprotein in pediatric nonalcoholic fatty liver disease: a pilot study. Arch Pediatr Adolesc Med. 2009; 163(7): 674-675.

13. Norris AL, Steinberger J, Steffen LM, Metzig AM, Schwarzenberg SJ, Kelly AS. Ciculating oxidized LDL and inflammation in extreme pediatric obesity. Obesity. 2011; 19(7): 1415-1419.

14. Taskinen MR, Adiels M, Westerbacka J, Soderlund S, Kahri J, Lundbom N, et al. Dual metabolic defects are required to produce hypertriglycerdidemia in obese subjects. Arterioscl Thromb Vac Biol. 2011;31 (9): 2144-2150

15. Machado MV, Cortez-Pinto H. Non-invasive diagnosis of nonalcoholic fatty liver disease. A critical appraisal. J Hepatol. 2013; 58: 1007-19.

16. Hernaez R, Lazo M, Bonekamp S, Kamel I, Brancati FL, Guallar E et al. Diagnostic accuracy and reliability of ultrasonography for the detection of fatty liver: a meta-analysis. Hepatology. 2011;54: 1082-90

17. Dasarathy S, Dasarathy J, Khiyami A, Jospeh R, Lopez R, McCullough AJ. Validity of real time ultrasound in the diagnosis of hepatic steatosis: a prospective study. J Hepatol. 2009 : 51 : 1061-7.

18. Joseph AE, Saverymuttu SH, al-Sam S, Cook MG, Maxwell JD. Comparison of liver histology with ultrasonography in assessing diffuse parenchymal liver disease. Clin Radiol. 1991;43:26-31.

19. Duseja A. Nonaalcoholic fatty liver disease in India: a lot done, yet more required. Indian J Gastroenterol. 2010;29: 217-25.

20. Day CP, James OF. Steatohepatitits: A tale of two hits? Gastroenterology. 1998; 114: 842-845.

21. Marchesini G, Brizi M, Morselli-Labate AM, Bianchi G, Bugianesi E, McCullough AJ, et al. Association of non-alcoholic fatty liver disease with insulin resistance. Am J Med. 1999;107:450-55.

22. Donnelly KL, Smith CI, Schwarzenberg SJ, Jessurun J, Boldt MD Parks EJ. Sources of fatty acids stored in liver and secreted via lipoproteins in patients with nonalcoholic fatty liver disease with insulin resistance. J Clin Invest. 2005; 115:1343-1351.

23. Sanyal AJ, Campbell-Sargent C, Mirshahi F, Rizzo WB, Contos MJ, Sterling RK, et al. Nonalcoholic steatohepatitis: association of insulin resistance and mitochondrial abnormalities. Gastroenterology. 2001; 120: 1183-1192.

24. Marchesini G, Moscatiello S, Di Domizio S, Forlani G. Obesity associated liver disease. J Clin Endocrinol Metab. 2008; 93: S74-S80

25. Targher G, Marra F, Marchesini G. Increased risk of cardiovascular disease in nonalcoholic fatty liver disease: causal effect or epiphenomenon? Diabetologia. 2008; 51: 1947-53.

26. Kotronen A, Yki-Jarvinen H. Fatty Liver: a novel component of the metabolic syndrome. Arterioscl. Thromb. Vasc. Biol. 2008;28: 27-38.

27. Dick TJ,Lesser IA,Leipsic JA, Mancini GB, Lear SA. The effect of obesity on the association between liver fat and carotid atherosclerosis in a multi ethnic cohort. Atherosclerosis. 2013; 226: 208-13.

28. Sung KC, Wild WH, Kwag HJ, Byrne CC. Fatty liver, insulin resistance and features of metabolic syndrome: relationship with coronary artery calcium in 10,153 people. Diabetes Care. $2012 ; 35$ : 2359-2364.

Copyright: (C) the author(s), publisher. Asian Journal of Medical Radiological Research is an Official Publication of "Socicty for Health Care \& Research Development". It is an open-access article distributed under the terms of the Creative Commons Attribution Non-Commercial License, which permits unrestricted non-commercial use, distribution, and reproduction in any medium, provided the original work is properly cited.

How to cite this article: Murthy MC, Shettty KBK, Ganesh K, Monteiro FNP. Correlation of Sonographic Grading of Renal Cortical Echogenicity with Serum Creatinine in Patients with Chronic Kidney Disease. Asian J. Med. Radiol. Res. 2018;6(1):26-29.

DOI: dx.doi.org/10.21276/ajmrr.2018.6.1.7

Source of Support: Nil, Conflict of Interest: None declared 